\title{
Emerging Ways to Conquer Education Challenges in Times of COVID-19 and Their Influence on Students' Academic Performance
}

\author{
Pooya Niksiar \\ The Citadel \\ Monika Bubacz \\ The Citadel \\ Deirdre Ragan \\ The Citadel \\ Gafar Elamin \\ The Citadel \\ Patrick Bass \\ The Citadel
}

Higher education has been faced with a particular set of challenges in response to COVID-19. To ensure continuous and quality education for students, our institution adopted two class attendance modes: 1) A traditional face-to-face (F2F) teaching mode and 2) A Hybrid teaching mode. In the Hybrid mode, half of the class meet online via videoconferencing software while the other half meet face-to-face. In this paper, we investigate both qualitatively and quantitatively student perceptions of course content and learning effectiveness when comparing the delivery modes. Through surveys and daily class comprehension quizzes, we were able to observe and compare performance as it correlates with class attendance mode. Quiz performance was specifically tracked to assess the impact of online versus F2F teaching. Surveys were implemented at the beginning and at the end of the semester to probe student perception and sentiment toward these course delivery modes in three dimensions; strengths, weaknesses, and grade expectations, using a questionnaire survey administered to $(n \sim 250)$ students.

Keywords: Instructional Delivery Mode, student perceptions, teaching effectiveness, online learning

\section{INTRODUCTION}

\section{Features of the Courses}

This study focused on adjustments that took place during the Fall 2020 semester as the institution was responding to COVID-19 restrictions. The institution did conduct the entire semester in as undisrupted learning environment as possible. The residential students lived in the residential halls and attended classes 
on campus; the non-residential students were welcomed onto campus for classes. COVID-19 restrictions included mask-wearing at all times while in classroom and open spaces on campus in addition to adhering to distancing guidelines. Given the small size of some classes, it was possible to continue to offer these classes in the traditional face to face mode. However, some of the classrooms were too small and unable to accommodate all of the registered students at the required distancing; in these cases, the institution chose to follow a hybrid structure. These hybrid courses alternated the students between attending face to face and attending remotely via a Zoom connected through an iPad on a Swivl ${ }^{\mathrm{TM}}$ robotic base. Quarantined students only attended remotely via Zoom. Also, a select number of courses used an online, asynchronous delivery mode.

Regardless of the mode of instruction (face to face, hybrid, or online), all quizzes and course final exams were completed online through the institution Canvas Learning Management System (LMS) with the students in a remote location. Other exams were completed through the Canvas LMS; students could elect to either be in the classroom or be in a remote location. All exams completed remotely required the use of LockDown Browser ${ }^{\circledR}$ with Respondus Monitor ${ }^{\circledR}$ for distance exam proctoring. Many students preferred to take exams in the classroom both to use the fairly reliable internet connection in the academic buildings and to avoid the use of LockDown Browser® with Respondus Monitor®.

The selected courses include multiple Mechanical Engineering junior and senior year undergraduate courses and graduate level Mechanical Engineering and Project Management courses. All of these courses were lecture based courses with calculations, modeling and analysis involved, some of courses included laboratory as well. These courses were; Thermal Fluid Systems (MECH 310), Engineering Materials (MECH 304), Advanced Materials (MECH 404), Modeling Analysis I (MECH 350), Lightweight Structures (MECH 478) and Advanced Mechanics of Materials (MECH 604).

\section{Instructor Backgrounds}

The instructors for the selected courses have varied backgrounds and status. The instructors all have at least a few years of experience in teaching; their current roles vary from instructor to associate professor while their backgrounds include military, industry, and government experience. While generally very techsavvy, these instructors have somewhat limited experience being students themselves in a class delivered online or in a hybrid fashion.

\section{Institutional Details}

The institution offers Bachelor of Science and Master degrees in Engineering. The institution has two main undergraduate constituents: (1) residential, full-time students who live and study in a militarystructured learning environment taking only daytime classes and (2) non-residential part-time students who participate in classes mainly in the evenings. All graduate students are non-residential part-time students with jobs outside of the institution.

The day students have numerous military obligations and restrictions that impact their daily academic experience. For example, day students have fairly small classes ( $<28$ students), mandatory class attendance, and focused institution-wide study periods each evening. Additionally, the day students have codes of conduct and standards of appearance that must be followed whenever outside of the residential hall. The residential campus is compact and can be navigated from side to side in less than ten minutes on foot.

The evening undergraduate and graduate students generally have even smaller class sizes $(<21$ students). These students, however, tend to live and work far enough from the institution that driving time and traffic in the evening can be a frustration.

These institutional and student life factors may impact the students' preferred learning modes.

\section{Literature Review}

With COVID-19 educational changes, there is an increasing amount of literature probing the impact of learning mode on student learning and sentiment. Teaching modes shifted quickly last spring as COVID19 caused many institutions to adapt to online teaching modes. This mode shift has had challenges, including technology issues, a drop in student and instructor interaction, distraction, and a lack of effective 
clinical or laboratory-related teaching (Verma et al., 2020). Instructors are often less comfortable in the new online teach roles which require additional management and organization activities in addition to new pedagogical practices (Redmond, 2011)(Martin et al., 2019). Perhaps connected to this, students perceive that online learning required more time as instructors assign more tasks (Coman et al., 2020). When comparing face to face to online learning, students feel that academic success comes from in-class interactions such as face time with the instructor, participation in hands-on activities, class discussions, and small group work. Even online students felt that feedback from the instructor was helpful, suggesting that the instructor is a significant driving force in learning for both face to face and online students (Hurlbut, 2018).

Hybrid learning, incorporating face to face and online learning, can offer the opportunity for effective and efficient instruction. Effectively implementing hybrid instruction requires a deliberate definition of roles for the teacher and learner, of task objectives, and of the tools and resources needed (Masson et al., 2008). Students like that hybrid instruction provides increased access to higher education; flexible scheduling taking courses based on the learner's schedule, location preference for the learner to consume the material, and reduced travel costs (Ackerman, 2008). Additionally, students appreciate the ability to look at material online repeatedly for improved comprehension (Yang \& Spitzer, 2020). On the other hand, hybrid learners do report a reduced sense of belonging (Ackerman, 2008). Previous research has established the differences in affective and cognitive learning outcomes achieved through traditional and remote learning. Remote learning can produce decreased affective learning but comparable cognitive learning. Social presence and interaction strategies can improve student and instructor enjoyment, connection, and overall learning (Mackey \& Freyberg, 2010).

Additionally, the incorporation of technology tools may create expanded options for achieving learning objectives. Recorded lectures, videos, graphics, illustrations, audio files, and traditional written words can all be combined to create an impactful classroom learning experience (Dey et al., 2009). Furthermore, introducing new concepts via some of these technology tools, when assigned as class preparation assignments, could improve learning (Ellis, 2008). As an extension, utilizing short videos introducing a key new concept or exam or homework solutions could scaffold course concepts for the learner (J. W. Lee et al., 2008). The aforementioned techniques utilized outside of class time would create the opportunity for class time to be used for active learning exercises involving interactions between the student and instructor (GREEN katierae@umich.edu et al., 2012). Note that these techniques can be used for both face to face classes and remote classes. In fact, when probed, students preferred face to face instruction with online learning supplementing the class content (Coman et al., 2020).

Computer-based exams can be offered via a variety of learning management systems for face to face, remote, and online classes. One benefit to the instructor includes automatic grading and asynchronous scheduling. Students are not always adept at approaching this asynchronous timing as they must chose a time, within the offered window, to complete the exam. Research has shown better performance when the exam is taken earlier in the available window (Coman et al., 2020). Unfortunately, weaker students tend to complete the exam later resulting in lower academic performance (Chen et al., 2019).

\section{PROCEDURE DESIGN}

By COVID-19 imposed restrictions, the institution decided to adopt strengths of F2F and online teaching modes to maximize education effectiveness. For this purpose, hybrid teaching mode was used, in which the students still could benefit from in person attendance and required portion of the class attend in person by following CDC social distancing protocols while the rest of the class was? attending via Zoom. One concerns regarding online teaching was decreased class participation. For this purpose, we designed class activities in form of short quizzes to engage students and encourage participation. The quizzes were based on materials taught the same day and students completed quizzes during the class time or after class depending on the course structure and timing. One of the advantages of online teaching was the access to recorded lecture to go over it after the class for better understanding. Also, based on the literature review, in online teaching mode weaker students perform better in synchronous lectures than in asynchronous. All 
of our lectures were synchronous with an exception for Election Day, when lectures were recorded and shared with students beforehand. The results of this different style of delivery were on students' performance was investigated. Also, we gave exams online as students prefer online exams as they can take it in a preferred and comfortable place with less environmental disturbances.

TABLE 1

\section{QUESTIONNAIRE GIVEN TO STUDENTS AT THE BEGINNING AND END OF SEMESTER}

Question 1: What is your preferred mode of education? Select one.
(a) Online
(b) in person/F2F

Question 2: Explain your reasons for the answer to Question 1?

Question 3: In your opinion, what are strengths of online teaching?

Question 4: In your opinion, what are limitations of online teaching?

Question 5: In your opinion, what are strengths of in-class / face-to-face teaching?

Question 6: In your opinion, what are limitations of in-class / face-to-face teaching?

Question 7: In your opinion, what are strengths of hybrid teaching?

Question 8: In your opinion, what are limitations of hybrid teaching?

Question 9: On scale of 1 to 10, rate your preference regarding online education. (10 being 'I

absolutely love it!')

Question 10: On scale of 1 to 10, rate your preference regarding in class / face-to-face education. (10

being 'I absolutely love it!')

Question 11: On scale of 1 to 10, rate your preference regarding hybrid education. (10 being 'I

absolutely love it!')

Question 12: Compared to traditional mode of teaching, do you think your final grade in a course you

are taking in a hybrid mode will be:

Question 13: Do you think your final grade in a course you are taking online only will be:

(Skip this question if you are not taking any online courses.)
(a) Higher
(b) lower
(c) the same

Question 14: Please include any additional comments.

Next, we investigated openness of students to online teaching mode as we believed their perception regarding effectiveness of online/hybrid modes of teaching will affect their learning experiences. For this purpose, a survey was given to students at the beginning of semester and end of semester to investigate how their idea has changed regarding hybrid mode of teaching after experiencing it for one semester. The survey given to students is shown in Table 2 below.

For quantitative data standard deviations are shown as error bars in Figure 3-6. Finally, to find area for improvements beyond those strategies mentioned in literature, we asked about strengths and weaknesses for each mode of teaching in Questions 3-8, 14.

\section{RESULTS}

\section{Student Perception Results}

The data were collected from all courses and were combined to be analyzed collectively. The rate of response was $82 \%$. To learn about student's perception with respect to three modes of teaching (face to face, online and hybrid) a survey was given to the students at the beginning of the semester. To investigate their experience of hybrid teaching, the same survey was given to them at the end of semester. Our institution has three groups of students; 1-day students, 2-evening students and 3-graduate students. Day students are full time residential students while evening and graduate students are non-residential part time students. First, they were asked about their mode of preference. As it can be seen from Figure 1(a), both day and evening students have higher preference for $\mathrm{F} 2 \mathrm{~F}$ at the beginning of the semester. Considering the fact that evening students have longer commute time to attend the classes, their higher tendency toward 
online teaching may be related to this. Next, we considered undergraduate population versus graduate students. The later grouping was important as in graduate or elective classes there was no curriculum obligation for students and students took the course because of their passion and have specifically selected that course, meaning they tend to be more invested in performing well. Figure 1(b) shows the similar trend as was seen in Figure 1(a) with a difference that graduate students had the same preference for online or hybrid teaching modes.

FIGURE 1

\section{PREFERRED MODE OF EDUCATION AT THE BEGINNING OF THE SEMESTER. (a) DAY STUDENTS ARE COMPARED TO EVENING STUDENTS. (b) UNDERGRADUATE STUDENTS COMPARED TO GRADUATE STUDENTS}
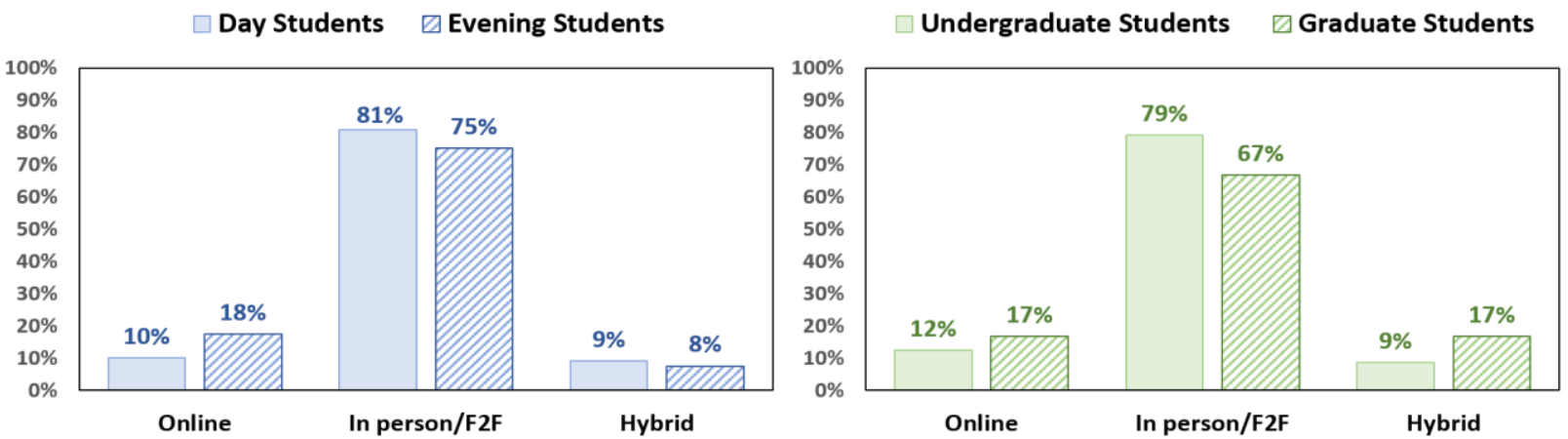

By comparing the survey results at the beginning and end of semester for all student population (i.e. day, evening and graduate students), we observed the same preference is kept while preference for F2F teaching was increased slightly by end of semester and preference for online teaching was decreased (Figure 2).

FIGURE 2

PREFERENCE OF ALL STUDENTS (i.e. DAY, EVENING AND GRADUATE) REGARDING MODE OF TEACHING (a) AT THE BEGINNING OF SEMESTER, (b) END OF SEMESTER

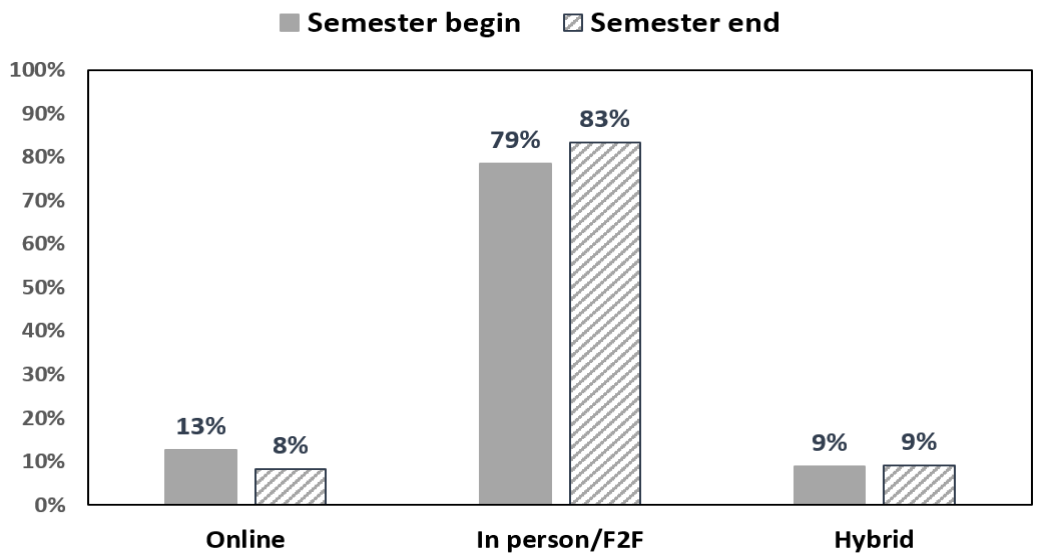

In this survey students were asked to choose either F2F, online or hybrid modes of teaching. To have better quantitative comparison, they were also asked to rate their preference with respect to three modes of teaching from 1 to 10; 1 being least favorable and 10 most favorable mode of teaching. Figure 3(a) shows F2F mode of teaching is a preferred one similar to the trend observed in Figure 1 with a difference that 
rating of F2F and online/hybrid teaching modes is not as big as in Figure 2. This demonstrates there are potentials for online and hybrid teaching modes and by adopting practices compatible with online/hybrid teaching and appropriate use of technology in the classes they can be competitive to F2F teaching.

Also, students were questioned about their anticipation of how their grade will be affected by going from F2F to online teaching mode. Figure 3(b) shows about 45 percent expected lower grade and this number was increased by end of the semester.

\section{FIGURE 3}

\section{(a) RATING OF STUDENTS WITH RESPECT TO ONLINE, FACE-TO-FACE AND HYBRID MODE OF TEACHING AT THE BEGINNING AND END OF SEMESTER. (b) PREFERRED MODE OF EDUCATION, (b) STUDENT'S GRADE EXPECTATION}
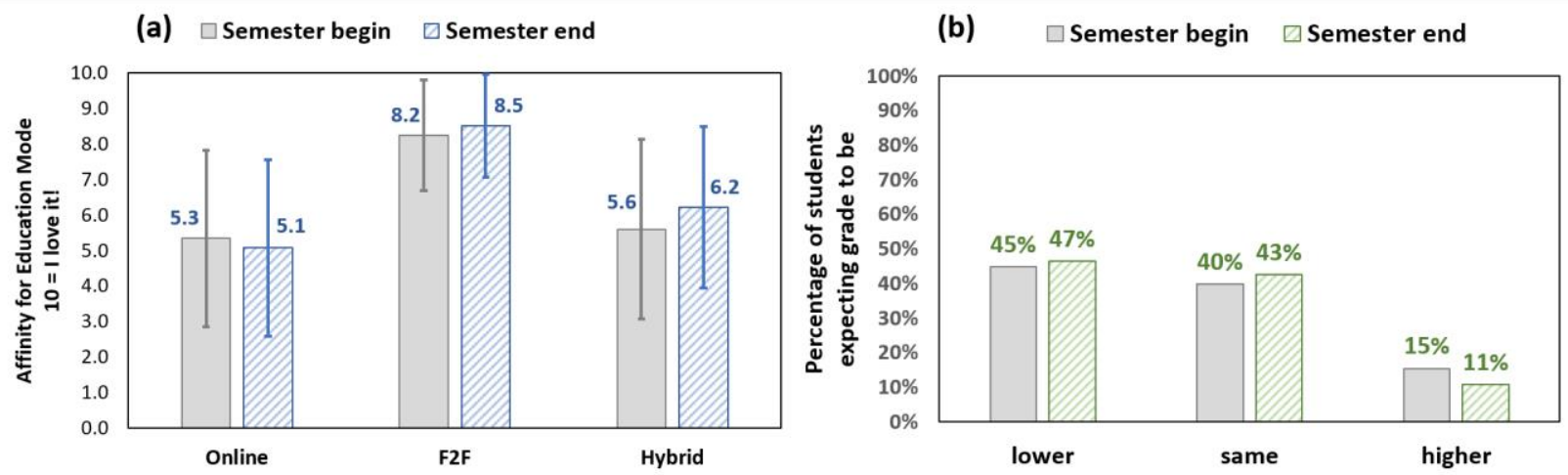

\section{Student Comments}

Students were also asked to provide perspective on their perceptions of the strengths and weaknesses of each mode of teaching. Six questions were included in the surveys to further understand the reasons for the students' preferences for different modes of teaching. The same survey, with the same sets of questions, was administered to students at the beginning and the end of semester.

For hybrid teaching, having access to recorded lectures and going over the lectures after the class to fully understand the materials and reflect on it, looking up relevant materials online simultaneously, selfpaced learning, flexibility regarding on campus presence and no need to commuting, making work-life balance less stressful and developing self -motivated individuals were benefits and strengths. For challenges and limitations, technological issues (e.g. limited camera view, audio/video delays and impairments, connection problems), distraction and less class participations were mentioned.

For online teaching benefits and strengths were; learning with own pace, staying at a comfortable place, discussion boards and learning more on their own. However, taking more time to finish the materials and distraction were challenge of online learning.

For F2F learning, better interactions with classmate and instructor, group learning, easier to take notes and see the board and better engagement during lectures were strength of F2F learning. Regarding challenges and limitations, traffics and time spent to commute to campus and being exposed to COVID-19 were mentioned. Table 2 summarizes strengths and challenges of F2F, online and hybrid teaching modes.

It is important to note that some of these comments definitively link to the classroom experience at the institution, where traditionally classrooms are small, as is the ration of students to instructors and the class attendance is mandatory with consequences for absence or even tardy arrival. Online and hybrid education modes impact these institutional constraints regarding the classroom experience. 
TABLE 2

STRENGTHS AND CHALLENGES OF F2F, ONLINE AND HYBRID MODE OF TEACHING

\begin{tabular}{|c|c|c|c|c|}
\hline & Benefits and Strengths & $\begin{array}{l}\text { Response } \\
\text { rate }\end{array}$ & $\begin{array}{l}\text { Challenges and } \\
\text { Limitations }\end{array}$ & $\begin{array}{l}\text { Response } \\
\text { rate }\end{array}$ \\
\hline \multirow{5}{*}{ Hybrid } & $\begin{array}{ll}- & \text { Recording can be } \\
& \text { rewatched, more resources }\end{array}$ & $\% 35.0$ & - $\quad$ Distracted & $\% 28.5$ \\
\hline & $\begin{array}{l}\text { - Best of both methods (F2F } \\
\text { and online) }\end{array}$ & $\% 33.7$ & - Limited camera view & $\% 23.3$ \\
\hline & $\begin{array}{l}\text { Develop self-motivation, } \\
\text { self-paced }\end{array}$ & $\% 12.9$ & - Tech issues & $\% 29.8$ \\
\hline & $\begin{array}{l}\text { Flexibility (work-life } \\
\text { balance) }\end{array}$ & $\% 36.3$ & $\begin{array}{l}\text { - Harder to participate/ask } \\
\text { questions }\end{array}$ & $\% 46.7$ \\
\hline & - $\quad$ Extra resources provided & $\% 32.4$ & $\begin{array}{l}\text { - Appropriate pedagogical } \\
\text { methods not adopted }\end{array}$ & $\% 9.0$ \\
\hline \multirow{4}{*}{$\begin{array}{l}\text { Face-to- } \\
\text { Face }\end{array}$} & - $\quad$ Interaction with teacher & $\% 50.6$ & $\begin{array}{ll} & \text { Less flexible } \\
& \text { (Traffic/drive time) }\end{array}$ & $\% 23.3$ \\
\hline & - Interaction with classmates & $\% 24.6$ & - Threat of COVID-19 & $\% 9.0$ \\
\hline & - $\quad$ Easy to ask questions & $\% 48.0$ & $\begin{array}{l}\text { - Limited access to } \\
\text { materials }\end{array}$ & $\% 25.9$ \\
\hline & - Board is easy to read & $\% 19.4$ & $\cdot$ & \\
\hline \multirow[t]{2}{*}{ Online } & - $\quad$ Self-paced & $\% 32.4$ & $\begin{array}{l}\text { Hard to communicate, } \\
\text { Less interaction with the } \\
\text { professor }\end{array}$ & $\% 46.7$ \\
\hline & - Comfortable at home & $\% 28.5$ & $\begin{array}{l}\text { Technical issues, Bad } \\
\text { connection, Horrible } \\
\text { wifi, terrible quality } \\
\text { picture }\end{array}$ & $\% 31.1$ \\
\hline
\end{tabular}

\section{Students Performance Results}

Next, we investigated the correlation between student's perception about best mode of teaching and their performance in the classroom or online. In this regard, we designed six quizzes and gave them in seven different classes. The quizzes were administrated in a way that each student took three quizzes online and three quizzes in class. As it can be seen from Figure 4, students performed better in all seven courses when they took the quizzes in class. Considering each quiz individually, we observe both day students and evening students performed better in class for all six quizzes (see Figure 5). Even considering graduate students or students in elective courses with higher interest for the topic, performed better in class for most of quizzes (see Figure 6). 
FIGURE 4

PERFORMANCE OF STUDENTS THROUGH THE QUIZZES ACROSS SEVEN CLASSES WHEN TAKING THE CLASS ONLINE VERSUS FACE-TO-FACE. ERROR BARS ARE STANDARD DEVIATION

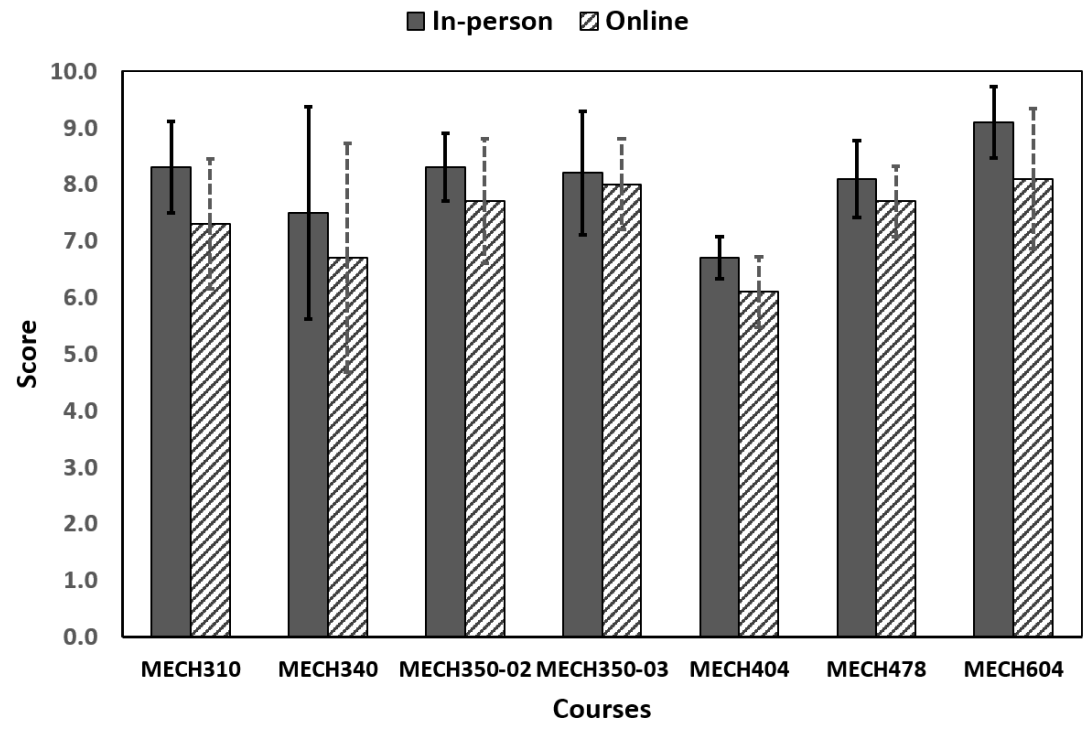

FIGURE 5

RESULTS OF SIX QUIZZES FOR DAY AND EVENING STUDENTS TAKING IN EITHER FACE-TO-FACE OR ONLINE MODE. ERROR BARS ARE STANDARD DEVIATION

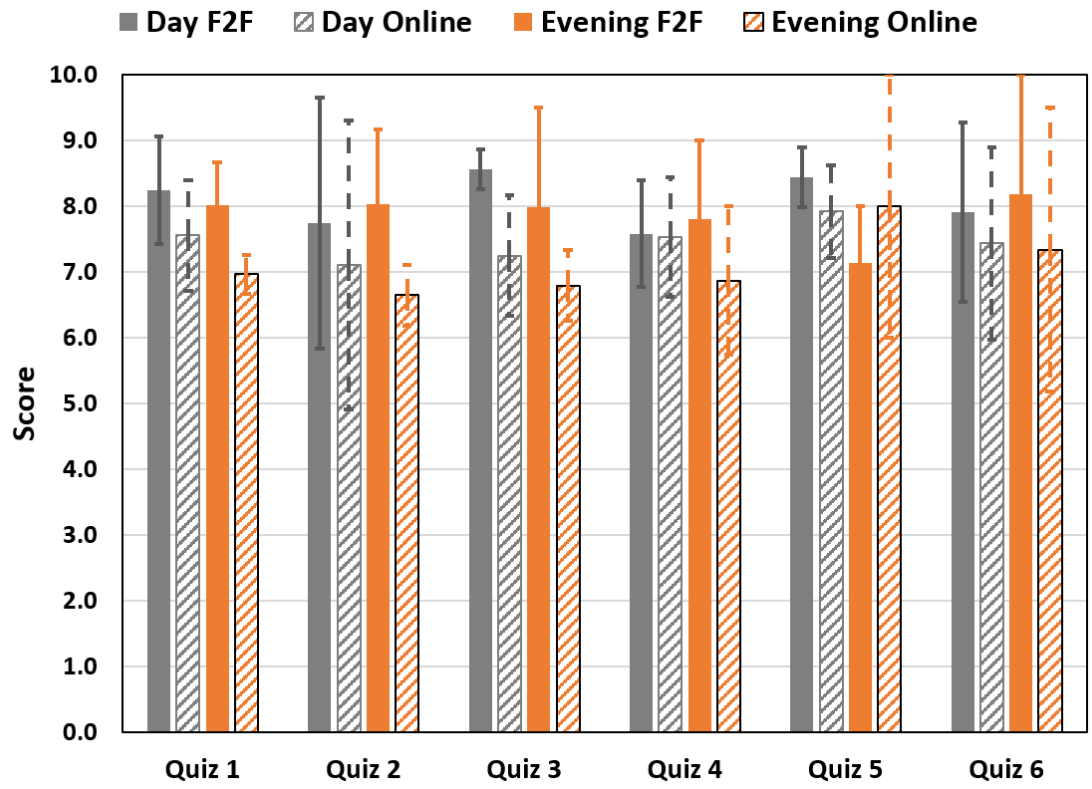




\section{FIGURE 6}

\section{RESULTS OF SIX QUIZZES FOR GRADUATE (OR ELECTIVE) VERSUS REQUIRED UNDERGRADUATE COURSE. ERROR BARS ARE STANDARD DEVIATION.}

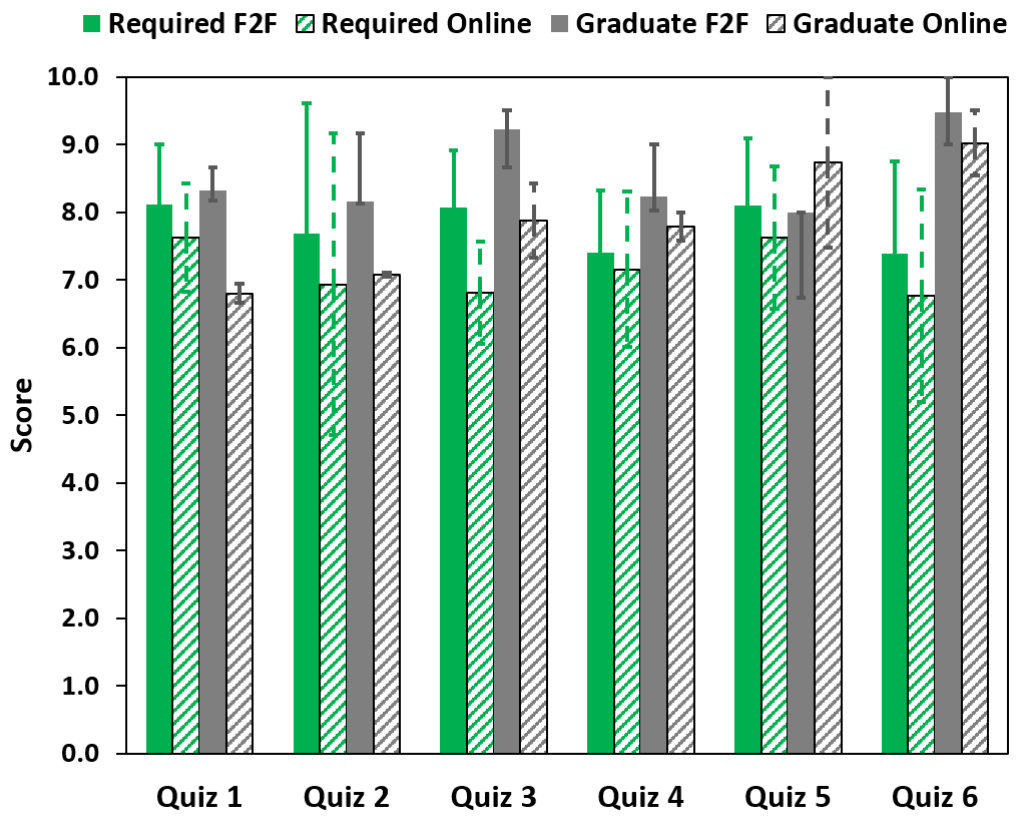

\section{Asynchronous Learning}

The entire population of students was exposed to asynchronous online education mode on the Election Day. In normal pre-pandemic conditions, day students would have regular classes while evening students would have no classes that day with an extra session schedule at the beginning or the end of the semester. Due to COVID-19 restrictions student travel was kept to minimum with Election Day being one of a few exceptions. Both, students and faculty, were made responsible to preparing and attending asynchronous online lectures. More than eighty students in five sections of three courses including undergraduate day, undergraduate evening and graduate students were surveyed after the final examination. Three questions asked about the asynchronous lectures, how much of them where reviewed and when and why if not. As expected graduate students reviewed the lectures more thoroughly, however day undergraduate students reviewed more that evening undergraduate students (see Figure 7). The reasons for nor reviewing the lecture show that day students did not have time while graduate students considered the material not important (see Figure 8). Finally, the selection of timing of the class review shows that undergraduate students are more apt to review the online material when presented while graduate student prefer flexibility as shown in Figure 9. About $20 \%$ of all students reviewed the lecture just before the final examination. 
FIGURE 7

RESULTS OF POST-FINAL EXAMINATION SURVEY RELATED TO THE AMOUNT OF REVIEWING OF THE ELECTION DAY ASYNCHRONOUS LECTURE

- Day Undergrad DEvening Undergrad \Grad

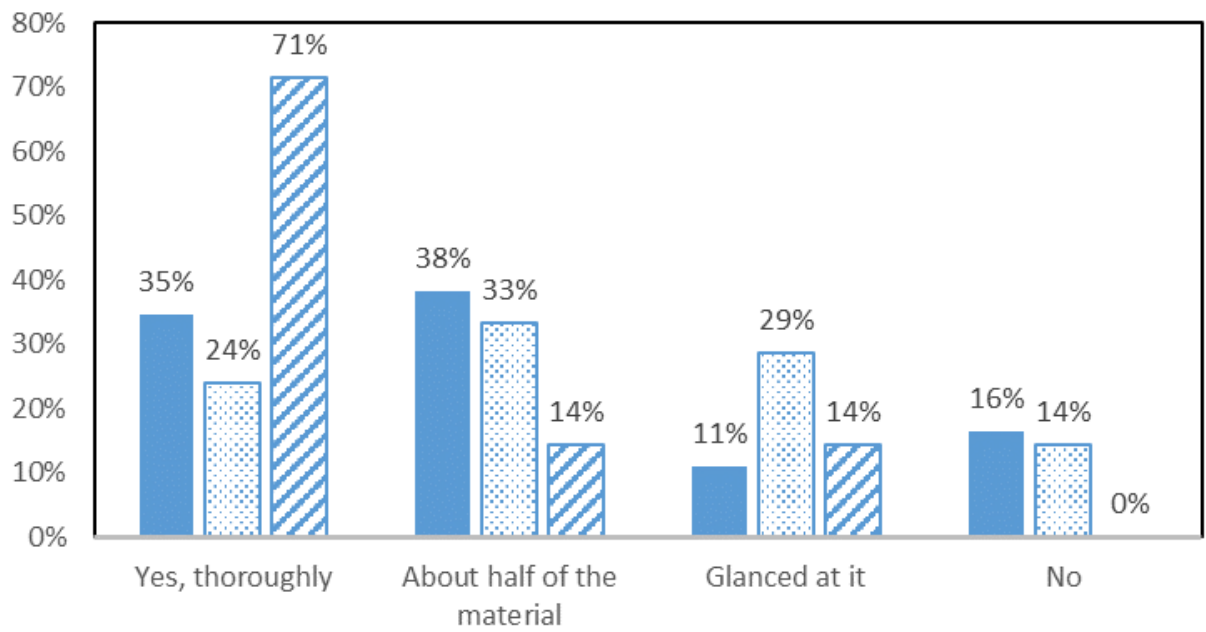

FIGURE 8

RESULTS OF POST-FINAL EXAMINATIONS SURVEY RELATED TO THE REASONS FOR NOT REVIEWING OF THE ELECTION DAY. ASYNCHRONOUS LECTURE.

- Day Undergrad ĐEvening Undergrad $\square$ Grad

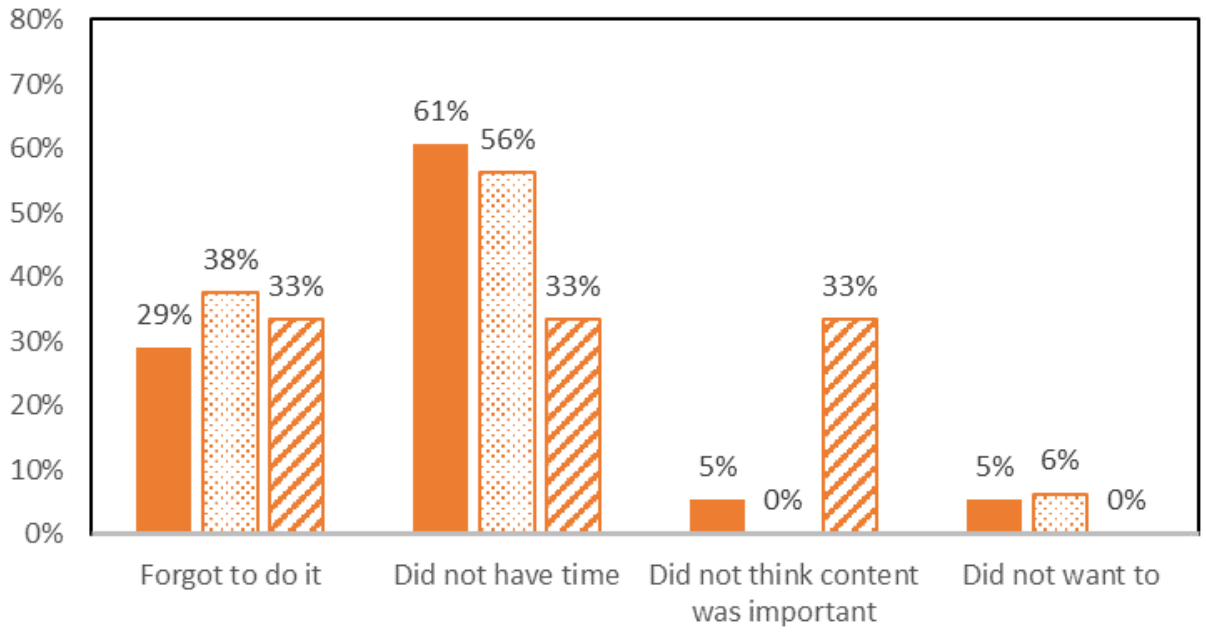




\section{FIGURE 9 \\ RESULTS OF POST-FINAL EXAMINATIONS SURVEY RELATED TO THE TIMING OF REVIEWING OF THE ELECTION DAY ASYNCHRONOUS LECTURE}

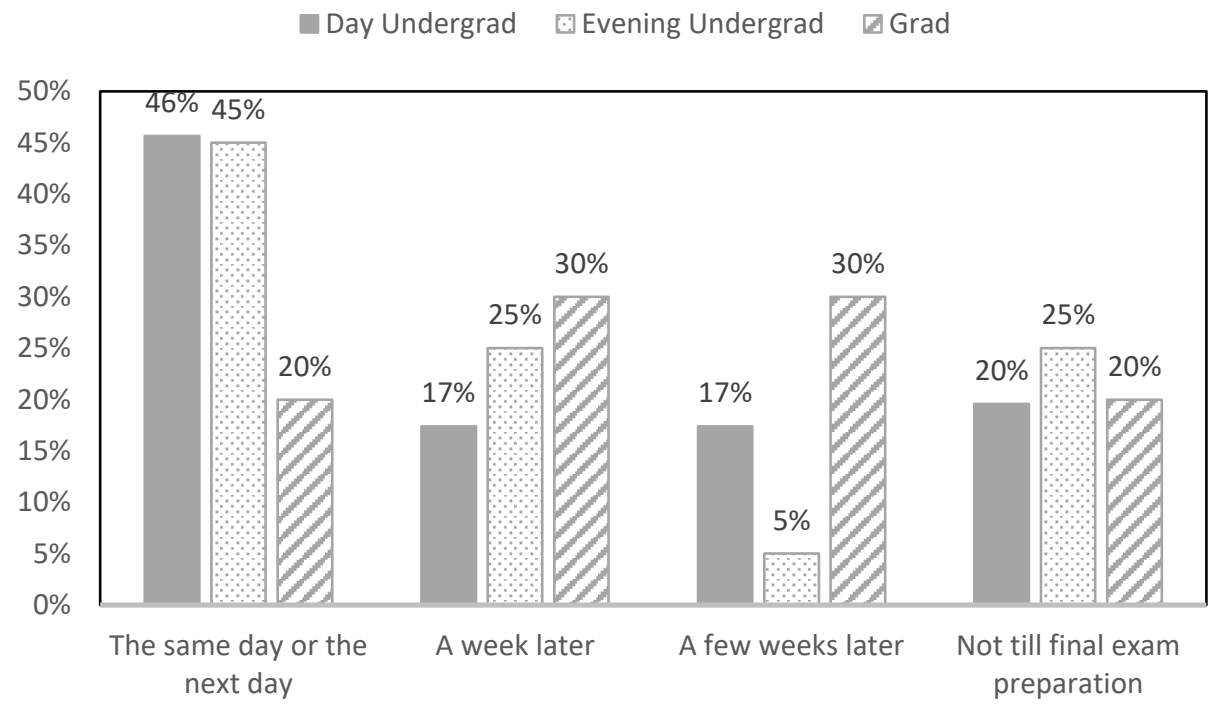

\section{CONCLUSION}

The day, evening, and graduate students at the institution were surveyed at the beginning and end of the semester to investigate their preference regarding face-to-face, online, and hybrid modes of teaching using multiple surveys and quiz results given in seven different courses using various modes of instruction. Based on survey results at the beginning of semester, face-to-face hybrid and online were preferred mode of teaching respectively. Surveys at the end of semester showed that face-to-face, online, and hybrid were the preferred mode of teaching, with hybrid being more favorable than online. This was verified by students rating and also comments. All students were required to attend an asynchronous lecture given on Election Day and showed that undergraduate students may be more invested in reviewing material on time but graduate students do it more thoroughly. From student comments, the main challenges of online teaching are distraction and loss of focus; not being able to interact with classmates or professor during lecture time; less class participation and engagement; distorted audio and limited camera views. However, several advantages regarding hybrid and online modes of teaching were mentioned by students: being able to repeatedly watch a recorded lecture to improve understanding of challenging lessons or those missed during the lecture time; ability to learn on individual pace and pause the recorded video whenever required; being flexible regarding time and place for class participation. This study shows that although the face-to-face mode of teaching was the most popular and the most efficient mode, there is a potential for the hybrid mode of teaching to be a more successful method of instruction as $24 \%$ of students mentioned in comments hybrid mode of teaching combined best of both methods ( $\mathrm{F} 2 \mathrm{~F}$ and online), provided technological issues are resolved and better engagement strategies are implemented.

\section{FUTURE RESEARCH}

Several areas for future research was noticed in students' comments. Although we implemented in-class activities to enhance engagement of those students attending the class via Zoom, there were complaints regarding asking questions and participation in class discussions. We are going to investigate new strategies to enhance convenience for online students to ask questions and participate in class activities. Also, limited view of board was mentioned from several students. For this purpose, new technological tools can be used such that instructor use laptop screen as board rather than white board. This let online student have better 
view of board. Finally, being less flexible was one of main weaknesses of F2F teaching. This requires investigation of several strategies to bring more flexibility in F2F teaching mode while not eliminating student attendance completely.

\section{ENDNOTE}

1. This study probed, both qualitatively and quantitatively, how course content was being received by our students. We gained a better understanding of the learning opportunities and limitations of various teaching modes.

\section{REFERENCES}

Ackerman, A.S. (2008). Hybrid Learning in Higher Education: Engagement Strategies. College \& University Media Review, 14(1), 145-158. Retrieved from http://ezproxy.lib.swin.edu.au/login?url=http://search.ebscohost.com/login.aspx?direct=true \&db= ehh\&AN=44881355\&site=ehost-live\&scope=site

Chen, B., West, M., \& Zilles, C. (2019). Analyzing the decline of student scores over time in selfscheduled asynchronous exams. Journal of Engineering Education, 108(4), 574-594. https://doi.org/10.1002/jee.20292

Coman, C., Țîru, L.G., Meseșan-Schmitz, L., Stanciu, C., \& Bularca, M.C. (2020). Online teaching and learning in higher education during the coronavirus pandemic: Students' perspective. Sustainability (Switzerland), 12(24), 1-22. https://doi.org/10.3390/su122410367

Dey, E.L., Burn, H.E., \& Gerdes, D. (2009). Bringing the classroom to the Web: Effects of using new technologies to capture and deliver lectures. Research in Higher Education, 50(4), 377-393. https://doi.org/10.1007/s11162-009-9124-0

Ellis, C. (2008). You Can't Do That in a Classroom!': How Distributed Learning Can Assist in the Widespread Adoption of Hybrid Learning Strategies. In J. Fong, K.R., \& F.L. Wang (Eds.), Hybrid Learning and Education (pp. 1-6).

Green, K.R., Pinder-Grover, T., \& Millunchick, J.M. (2012). Impact of Screencast Technology: Connecting the Perception of Usefulness and the Reality of Performance. Journal of Engineering Education, 101(4), 717-737. Retrieved from http://search.ebscohost.com/login.aspx?direct=true \&db=eue\&AN=83629857\&site=ehost-live

Hurlbut, A.R. (2018). Online vs. traditional learning in teacher education: A comparison of student progress. American Journal of Distance Education, 32(4), 248-266. https://doi.org/10.1080/08923647.2018.1509265

J.W. Lee, M., Pradhan, S., \& Dalgarno, B. (2008). The Effectiveness of Screencasts and Cognitive Tools as Scaffolding for Novice Object-Oriented Programmers. Journal of Information Technology Education: Research, 7, 061-080. https://doi.org/10.28945/179

Mackey, K.R.M., \& Freyberg, D.L. (2010). The effect of social presence on affective and cognitive learning in an international engineering course taught via distance learning. Journal of Engineering Education, 99(1), 23-34. https://doi.org/10.1002/j.2168-9830.2010.tb01039.x

Martin, F., Budhrani, K., Kumar, S., \& Ritzhaupt, A. (2019). Award-winning faculty online teaching practices: Roles and competencies. Online Learning Journal, 23(1), 184-205. https://doi.org/10.24059/olj.v23i1.1329

Masson, A., Macneill, Á., Murphy, C., \& Ross, V. (2008). The Hybrid Learning Model - A Framework for Teaching and Learning Practice. International Journal of Emerging Technologies in Learning (IJET), 3(0), 12-17.

Redmond, P. (2011). From face-to-face teaching to online teaching: Pedagogical transitions. ASCILITE 2011 - The Australasian Society for Computers in Learning in Tertiary Education, 2002, 10501060 .

Verma, A., Verma, S., Garg, P., \& Godara, R. (2020). Online Teaching During COVID-19: Perception of 
Medical Undergraduate Students. Indian Journal of Surgery, 82(3), 299-300.

https://doi.org/10.1007/s12262-020-02487-2

Yang, Z., \& Spitzer, L. (2020). A Case for Hybrid Learning: Using a Hybrid Model to Teach Advanced Academic Reading. ORTESOL Journal, 37, 11-22. Retrieved from

https://search.proquest.com/scholarly-journals/case-hybrid-learning-using-model-teachadvanced/docview/2454728768/se-2?accountid=17215\%0Ahttps://limo.libis.be/services/

KULeuven?url_ver=Z39.88-2004\&rft_val_fmt=info:ofi/fmt:kev:mtx:journal\&genre=article\&sid 